\title{
$\triangle C_{4}$ Osteopathic manifesto series
}

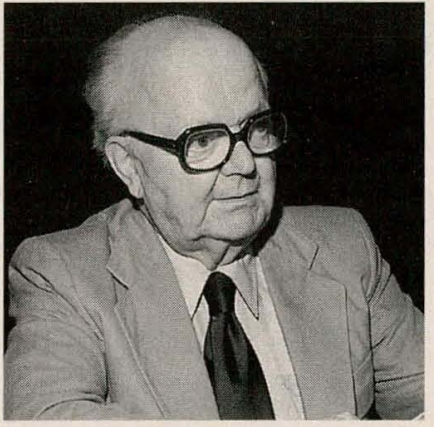

Editor's note: Editor Emeritus George W. Northup, DO, FAAO, died on December 12, 1996, at the age of 81. In tribute to his life-long service to the osteopathic medical profession, which included his tenure as Editor in Chief from 1961 to 1987, the JAOA is reprinting Dr Northup's Osteopathic Manifesto series, with only style changes. The original 12-part series ran in the JAOA, beginning in February 1981.

\section{Our distinct image}

Throughout its history, the osteopathic medical profession has remained organizationally separate and philosophically distinct from all other medical professions. The separateness of osteopathic medicine is no self-centered ideology. Osteopathic medicine was born to improve the practice of medicine and surgery, and that purpose has never changed. With great repetition we have stated this as our goal. How well we stick to that goal and develop it into progressive action will be a major factor in the profession's future.

Unfortunately, many people, both within the profession and outside of it, think of the basic concepts of osteopathic medicine as being solely related to structural diagnosis and manipulative therapy. The idea that an osteopathic physician is the same as any other physician except that he is trained to use manipulation violates the basic principles of the profession.

The purpose of osteopathic medicine was not to build a school of medicine solely around structural diagnosis and manipulative therapy. It was to supply a broadly based medical philosophy upon which a more holistic viewpoint of man - his health and his diseases — could be studied.

Although the musculoskeletal system in the maintenance of body health and as a factor in disease was and still is an important consideration, this basic point is a long way from being universally accepted. Despite the growing emphasis on manipulative therapy and problems existing in the musculoskeletal system by members of the allopathic profession, their viewpoint is a narrow one. They see manipulative therapy as an adjunct to physical medicine and useful in the treatment and management of the various aches and pains that occur within that system. However, they do not fully realize that the interrelationship of structure and function implies more than gross musculoskeletal problems and their manipulative treatment. This interrelationship pervades all elements of medicine. The fact that musculoskeletal problems are often a cause of dysfunction in other body systems should be recognized and stressed. Also, the role of musculoskeletal dysfunction as a mimicker of other disease syndromes should have high priority in a differential diagnosis.
As important as these concepts are, there are other important means of expressing our basic philosophy that are too often neglected.

The concept of the body as a melding of the physical, the mental, and the spiritual was emphasized by Dr Still himself. And yet, one only has to read the current medical literature to realize that the importance of this principle is a long way from universal recognition. The nutritional needs of the body in health and disease is another example. It has been only in the past decade that orthodox medical education has paid some attention to this.

Ancillary medical professions have developed to fill many vacuums in current medical education. Podiatry and optometry are good examples of professions that developed to handle these areas of neglect by physicians, both DO and MD.

Much attention has been given to our role in developing family practitioners. This objective must never be abandoned; in fact, it must be pursued with intensity. It brings balance and stability to the profession. We are appreciative and proud of our specialists because they help us center on many of the special intricacies of disease. However, a system of medicine that places too much emphasis on concentrated areas occasionally betrays any efforts to consider the total man. Osteopathic specialists, through their holistic training and through the basic philosophy of the osteopathic medical profession, should provide a broader view of medical problems than other specialists.

These principles and the others that make up the broad philosophy of osteopathic medicine need to be practiced rather than restated. How well we do this may determine our future.

We must not allow the distinctive image of our profession to fade and disappear. If we do, and our distinct image becomes an indistinct one, the government and the public will pose an uncomfortable question: Why two professions?

The answer is obvious. Our profession is determined to continue its role as a reform movement within the framework of total medical care. But to do so, our distinct image requires constant focusing.

\section{George W. Northup, DO, FAAO}

